\title{
TILLYARD'S WORK ON INSECT PHYLOGENY.
}

\author{
By J. G. Myers.
}

On 30th April the entomologcal seminary of the Bussey Institution, together with a considerable number of other Boston entomologists was privileged to hear Dr. R. J. Tillyard, Entomologist and Chief of the Biological Division of the Cawthron Institute, Nelson, New Zealand, lecture on his study of fossil insect and on the phylogeny of recent forms. At the same time the excellent photographs and d agrams shown as lantern slides, and still more the actual specimens of most of the important fossil forms enabled specialists present to form their own opinions as to the correctness of the lecturer's conclusions.

Dr. Tillyard was led, on venational considerations alone, to select or study the scorp on-flies as affording a central type which might serve as a guide to the relationships of several more specialised and larger orders of Holometabola. Comparative morphology proved inadequate as a sole means of elucidating these relationships but the rich finds of ate Palaeozoic (Upper Permian) and early Mesozoic (Upper Triassic) insects in Australian rocks supplied at once an extremely valuable series to help bridge the gap between the Carboniferous fossils of Europe and North America and the Liassic remains of England and Germany. This hiatus in the palaeo-entomological record was almost completely filled by the discovery of a wealth of forms in the Lower Permian of Kansas.

Until Dr. Tillyard's work there was little palæontological evidence as to the origin of the more highly specialised and dominant groups of modern insects-Lepidoptera, Diptera, $\mathrm{Hy}$ menoptera, Coleoptera, Hemiptera. The first contribution on the Permian and Triassic insects of Australia confirmed the very close relationship subsisting between Trichoptera and Lepidoptera and established the probable origin of the Diptera, Lepidoptera, Trichoptera, Neuroptera and Mecoptera from a Mecoperoid stem. A very convincing and practically complete venational series was shown by slides and specimens to culminate in modern 
lepidopterous and dipterous types. An interesting backward extension of the series afforded by the discovery of true Mecoptera in the Kansan Lower Permian places the origin of holometaboly back at least half a geological period. The Upper Carboniferous Metropator, a fossil from the earliest horizon yet known to furnish insect remains, is now believed to be a true Mecopteron, leading to the possibility that complete metamorphosis may have evolved even earlier and that the ancestors of the present Panorpoid Holometabola may have been not merely Mecopteroid but actually Mecopterous.

Perhaps the most interesting link in the phylogeny of the Neuroptera is afforded by the Lower Permian Protomerope, in which the strong series of costal veinlets, the form of Sc and the abundant branching of $\mathrm{Rs}$ and of $\mathrm{M}$ lead at once to the condition exhibited by primitive Neuroptera.

The Australian fossils threw no light on the relationships of the Hymenoptera. There were indications that this order was related to those composing the "Panorpoid complex," but no definite venational types from which the hymenopterous condition could be derived. It remained for the Kansan Lower Permian to supply more definite information as to the origin of this order. In the beautifully preserved fossils for which has been founded the new order, Protohymenoptera Tillyard, the venation and texture are distinctly Hymenopteroid and yet show, especially in the number and position of the cross-veins, some evidence of Mecopteroid relationships. The divergences are, however, greater than the resemblances and the Protohymenoptera, with their supposed derivatives the Hymenoptera, are believed to have sprung from another stem than that which gave rise to all the other Holometabola. If, as the ecturer suggested, the hitherto enigmatical Sycopteron symmetricum Bolton from Commentry, France, belong also to the Protohymenoptera, then the origin of the Hymenoptera must be put back to the Upper Carboniferous.

The acceptance of Protohymen and its relatives as near to or identical with the ancestors of the Hymenoptera leads inevitably to the replacement of the complicated MacGi livray (1906) interpretation of the wing-venation in this order by a much 
simpler scheme comparable with that already suggested in the Homoptera by the Tillyard modification of the ComstockNeedham system The chief change concerns $\mathrm{Cu}$. The vein formerly known by this name becomes $\mathrm{Cu}_{1}$ while the stem called by Comstock $1 \mathrm{~A}+2 \mathrm{~A}$ is $\mathrm{Cu} 2+1 \mathrm{~A}$. The corresponding change in Homopterous horismology has now been accepted by every authoritative worker in the sub-order while the present modification seems to meet the approval of most of the Hymenopterists who have been able to examine the fossils. The differences in venation between Protohymenoptera and Hymenoptera may all be traced to specialisat on accompanying the evolution of a wing-coupling apparatus

In spite of the fact that as far back as the upper Trias of Australia true Coleoptera were the dominant insects, the origin of the order long remained obscure. True beetles occurred also in the upper Permian and with them primitive forms resembling Coleoptera but with flattened elytra furnished with a straight sutural margin and complete venation. These insects, constituting the new order, Protocoleoptera of Tillyard, were evidently nearly related to the ancestors of the Coleoptera, but their own affinities are very uncertain.

Outside the Holometabola the Hemiptera (sens. lat.) have long formed perhaps the most isolated of insectorders. The Heteroptera truly recognisable as such are recorded first in the Triassic, where they were already differentiated into quitespecialised gymnocerate and cryptocerate types. Fossils connecting this sub-order with more primitive forms are as yet unknown. With the Homoptera, however, the case is far different. Although the Protohemiptera, represented by Eugereon and by Mesotitan, are nothing at all to do with the Hemiptera, the Palæohemiptera have proved so definitely hemipterous that they are now apportioned among various fossil and recent familes of auchenorrhynchous Homoptera. Most of the upper Permian Homoptera are distinctly either auchenorrhynchous or sternorrhynchous. Pincombea is, however, in virtue especially of its well-developed clavus, possibly annectent, although predominantly sternorrhynchous. More generalised forms discovered in the lower Permian of Kansas have taken true Homoptera much 
further back in geological time and have indicated the steps in the evolution of the clavus. The original position of the wings at rest in these primitive Hemiptera was almost certainly stegopterous. The folding of the wings flat on the back was accompanied by the shortening and widening of the clavus and the thinning of the membrane distal of a line drawn transversely from the tip of the clavus to a point on the costal margin, that is, of those portions of the fore-wings which overlapped in the resting position. Thus was developed the hemielytral condition reaching its culmination in the typical heteropterous fore-wing. Conversely the lengthening and narrowing of the clavus led to the evolution of the type which reaches its highest development in the tegmen of the Homoptera Auchenorrhyncha.

The venation of the most primitive of the Homoptera from the Kansan lower Permian is derivable from a condition similar to that seen in Copeognatha from the same beds. Thus for the first time we have palæontological evidence for the view originally advanced by Börner from a consideration of the head structure and mouth-parts, that the Psocids and Hemiptera are related groups and that the latter with the Thysanoptera were derived from mandibulate ancestors by way of a Psocoid intermediate type. In the same complex obviously belong also the Anoplura, which are, however, much more closely related to modern Psocids through the Mallophaga. 

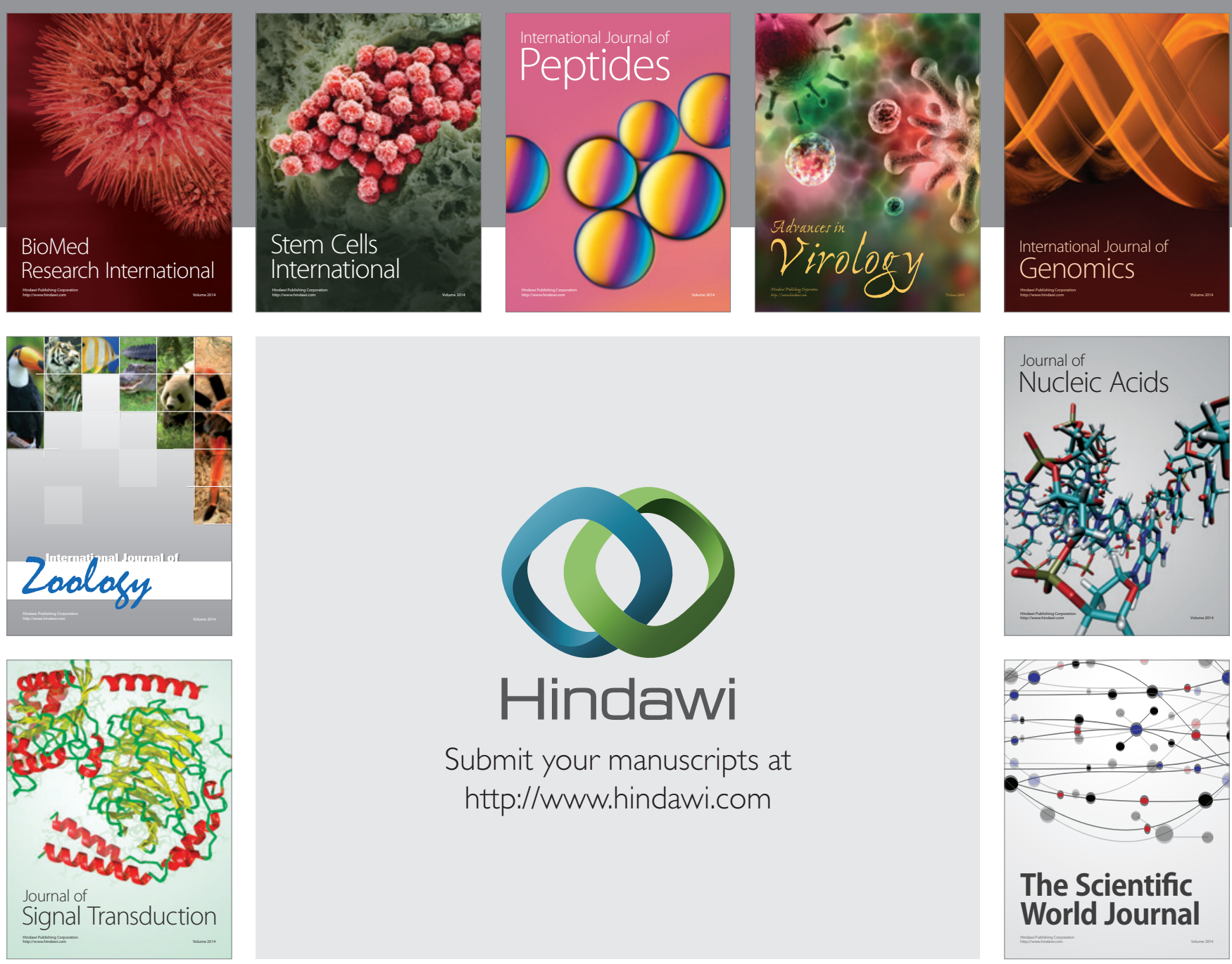

Submit your manuscripts at

http://www.hindawi.com
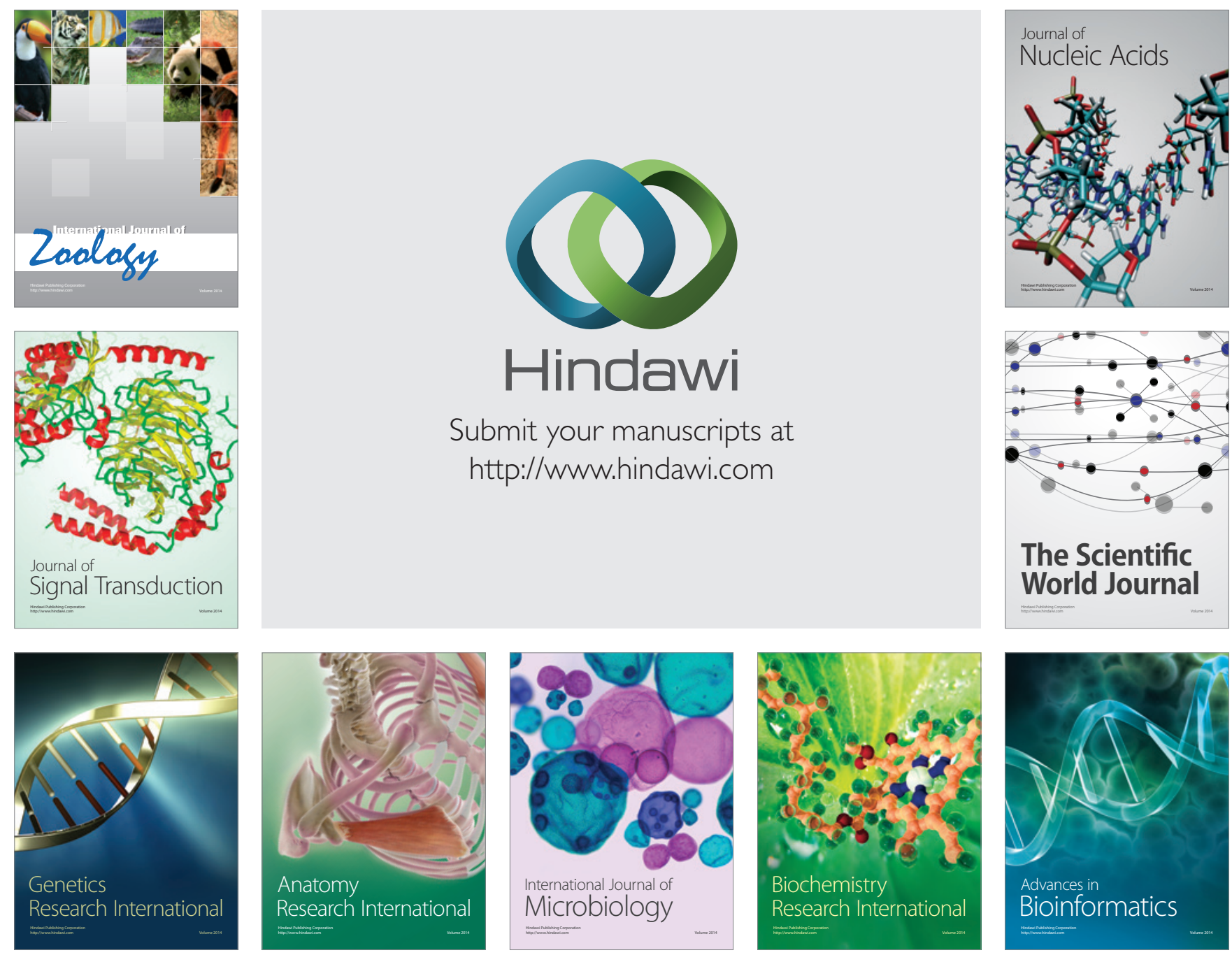

The Scientific World Journal
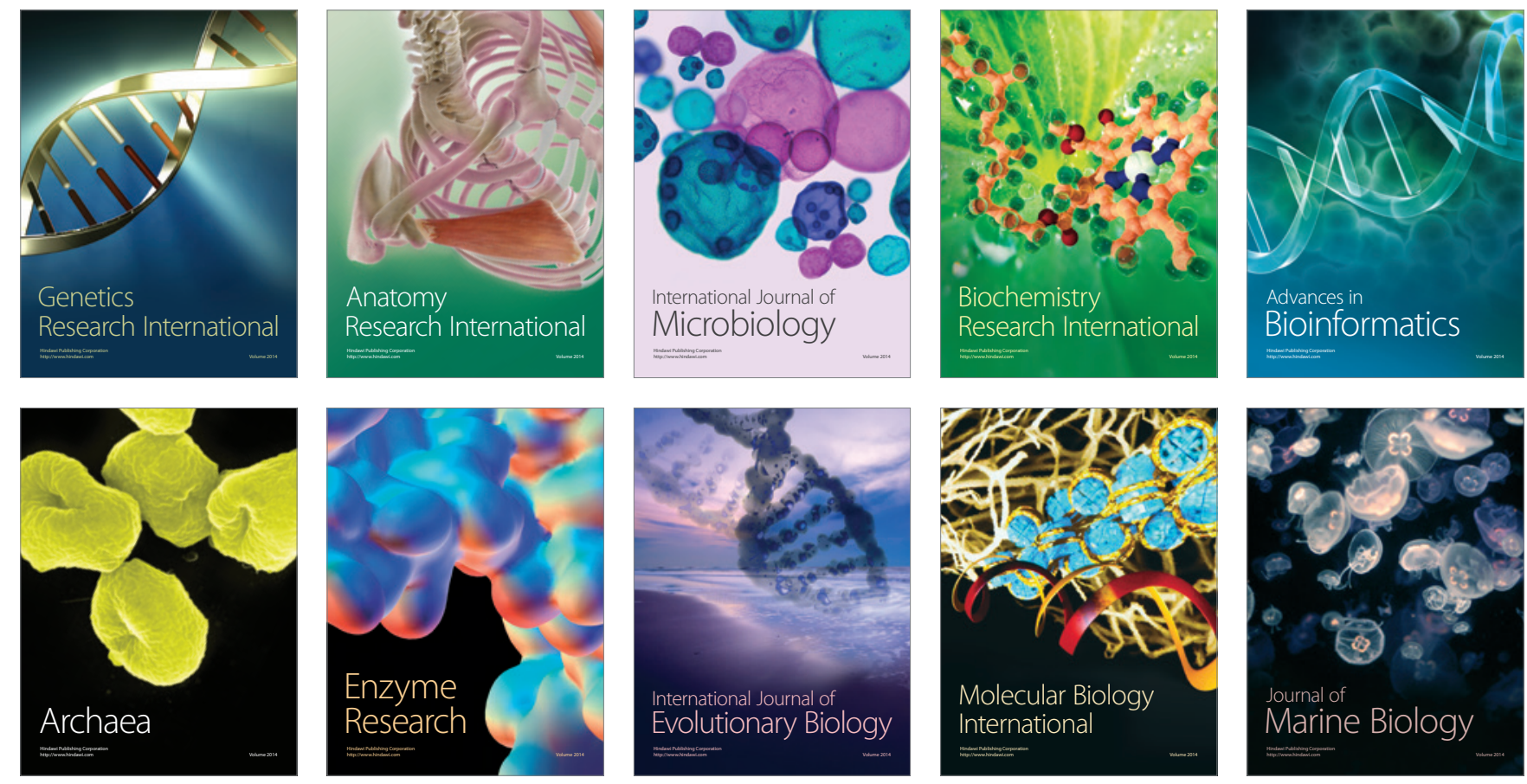